Esta revista forma parte del acervo de la Biblioteca Jurídica Virtual del Instituto de Investigaciones Jurídicas de la UNAM www.juridicas.unam.mx http://biblio.juridicas.unam.mx/

\title{
La reforma que viene: los temas a regular en materia política
}

\author{
Arturo Sánchez Gutiérrez \\ Margarita Moreno López
}

Sumario:
I. Introducción
II. Los temas en 2012
III. Los temas que vienen
IV. Conclusiones
V. Bibliografía 


\section{Introducción}

El año 2012 se caracterizó por la generación de nuevos debates en torno al proceso electoral federal. Los temas en el ánimo de los ciudadanos y de los actores sociales ya no estuvieron relacionados con el padrón electoral, la logística, ni la organización de las elecciones como en los años noventa; ni en el gasto de los partidos en los medios de comunicación o en la injerencia de actores externos al proceso electoral, como en 2000 y 2006.

En 2012, el eje de los cuestionamientos al proceso electoral estuvo centrado en el financiamiento ilegal de las campañas; el gasto excesivo por parte de los partidos políticos; la posible compra y coacción del voto; la presunta participación velada de los medios de comunicación y la discusión sobre el uso de las encuestas como propaganda política.

El Instituto Federal Electoral también fue cuestionado por su supuesta inactividad frente a los hechos que generaron controversias durante el proceso electoral. No obstante, actualmente esta autoridad sigue teniendo atribuciones acotadas. Por ejemplo, en términos de los recursos empleados en una campaña, el IFE sólo tiene facultades para actuar en caso de que los institutos políticos hayan erogado más dinero del que tenían permitido, asunto que normalmente se sabría casi un año después de la elección. El resto de los temas no está precisamente definido en el ámbito de las atribuciones del Instituto y depende totalmente de las acciones que lleven a cabo los actores en sus relaciones con las elecciones, como son las empresas mercantiles, los medios de comunicación y los encuestadores.

Muchas voces han llamado a llevar a cabo una nueva reforma electoral para evitar que los excesos y los abusos de los actores políticos se sigan dando. Sin embargo, la experiencia con la reforma electoral de 2007-2008 ha mostrado que la imposición de un modelo de comunicación política restrictivo en los contenidos, no solucionó los problemas relacionados con la emisión de propaganda política, electoral o gubernamental. El número de quejas en la materia y la obligación de resolverlas en poco tiempo, intensificó el proceso de judicialización del proceso electoral y proyectó aún más al IFE como un órgano dedicado a resolver procedimientos sancionadores, más que un órgano prioritariamente responsable de organizar las elecciones. Por lo demás, si bien se alcanzó algún nivel de equidad en la distribución de los espacios para la difusión de los promocionales entre los partidos polí- 
ticos, lo cierto es que prevalece la percepción de que durante las campañas se emite una cantidad exagerada de spots que no son bien recibidos por la audiencia y que tampoco comunican adecuadamente las propuestas de los candidatos, ni generan un sano debate democrático.

En el caso de la fiscalización de los recursos de los partidos, la decisión de la reforma de 2007-2008 en el sentido de crear una Unidad de Fiscalización autónoma, generó un distanciamiento del máximo órgano de dirección del IFE en el seguimiento a la forma como se llevan a cabo los procesos de fiscalización de los recursos de los partidos. Si bien el Consejo General es el órgano que aprueba los proyectos de resolución redactadas por la Unidad de Fiscalización, lo cierto es que el diseño de la fiscalización, el alcance de la revisión, los procedimientos de investigación y los criterios para determinar la existencia o no de irregularidades, no están en manos de los consejeros electorales. Por eso, el modelo actual no permite al Consejo General acompañar los trabajos como lo hacía la anterior Comisión de Fiscalización con el área encargada de la revisión de los informes anuales y de campaña de los ingresos y gastos de los partidos políticos. Con todo, tanto al interior del IFE, como entre los partidos y las sentencias del Tribunal Electoral, la satisfacción sobre el trabajo realizado apunta a que la fiscalización avanzó en los últimos años.

Finalmente, la instrumentación de las encuestas dependió de las empresas encuestadoras que las levantaron, y su difusión de los medios que las dieron a conocer. Ellos tendrán que pagar los costos políticos y de credibilidad sobre la manera cómo lo hicieron. A pesar de los contenidos en la ley electoral federal que regulan los tiempos y los requerimientos de calidad en los ejercicios demoscópicos, el dilema sigue estando en establecer las responsabilidades entre los que ordenan, diseñan, aplican, reportan, publican y difunden las encuestas.

De manera adicional, la reforma que viene deberá incluir contenidos que armonicen las reglas actuales con las modificaciones que se derivan de la última reforma constitucional en materia política, que se publicó en el Diario Oficial de la Federación el 8 de agosto de 2012. En dichas modificaciones se insertaron en la Constitución Política de los Estados Unidos Mexicanos las figuras de iniciativa ciudadana, consulta popular y candidaturas independientes, entre otras modificaciones. Cada una de estas figuras entraña por sí misma la emisión de reglas y con éstas nuevos retos para hacer que el tránsito hacia una democracia con mayor calidad sea una realidad. 
En las siguientes páginas se explicarán de manera detallada los principales cuestionamientos a la elección presidencial de este año, en torno al uso del dinero durante las campañas electorales; a la difusión de propaganda electoral, política y gubernamental; el uso de las encuestas como parte de la propaganda política, y las complejidad de la negociación política que tendrá que acompañar el diseño y aprobación de una reforma política que dé consistencia a los cambios ya anunciados públicamente por las principales fuerzas electorales.

Llevar a cabo la reforma no será una tarea fácil, toda vez que se requieren cambios profundos que no tendrían sentido sin contar con la anuencia de todos los actores políticos y sociales e, incluso, de la ciudadanía. Para evitar conflictos como los que se derivaron de la pasada reforma electoral, convendrá contar también con un reconocimiento y aceptación mínimo por parte de los sujetos regulados, que cada vez son más en materia electoral y que al igual que los medios de comunicación, tienen una importante participación en el modelo de elecciones que se ha dado el país.

En todo caso, la reforma electoral resulta indispensable si se quiere romper la dinámica de desconocimiento de los resultados electorales o del proceso en su conjunto, cada vez que se realiza una elección presidencial. Sea cual sea el objetivo de los impugnadores, revertir el resultado o anular la elección, el hecho es que los cambios deberán centrarse en satisfacer inquietudes para evitar suspicacias.

El dilema al momento de llevar a cabo el trabajo legislativo será encontrar un equilibrio entre la imposición de límites para evitar que se sigan reproduciendo los presuntos abusos, sobre todo en lo que respecta al uso del dinero durante las campañas electorales y la compra o coacción del voto, y el diseño de reglas más liberales y menos restrictivas de la actuación de los actores, principalmente en lo que toca a la difusión de propaganda político electoral.

\section{Los temas en 2012}

\section{Financiamiento ilegal y gasto excesivo de los partidos políticos}

Uno de los temas más debatidos desde el inicio de las campañas electorales de 2012, fue el excesivo gasto en que podrían haber incurrido 
los partidos políticos, particularmente el PRI y su candidato a la Presidencia de la República. Paralelamente, también desde el principio aparecieron indicios de financiamiento ilegal para las campañas, obtenido a través de una institución bancaria y la presunta utilización ilícita de tarjetas de una tienda de autoservicio.

Desde el inicio de las campañas electorales, el PAN y el PRD interpusieron quejas ante el IFE, por el presunto exceso de gasto en que estaba incurriendo el candidato Enrique Peña Nieto. Después de la elección, la coalición Movimiento Progresista y los representantes de los partidos que la integraban, PRD, PT y Movimiento Ciudadano, buscaron la nulidad de la elección presidencial a través del inicio de un juicio de inconformidad ante el IFE y el Tribunal Electoral del Poder Judicial de la Federación. ${ }^{1}$ Este documento acusaba al candidato Enrique Peña Nieto de haber incurrido en diversas violaciones a la ley que ameritaban la anulación de la elección. Entre otros puntos, se acusaba a la coalición Compromiso por México, integrada por el PRI y el PVEM, de haber rebasado los topes de gastos de campaña ${ }^{2}$ por la erogación de \$4599947 834.00. Con dichos recursos, obtenidos ilegalmente, el candidato del PRI-PVEM presuntamente había cometido conductas antijurídicas, como ejercer presión y coacción sobre los electores, para forzar el voto a su favor.

A decir de la Coalición quejosa, mediante la entrega de gratificaciones económicas y el reparto de bienes, especialmente entre los sectores más pobres de la sociedad, se habrían comprado votos. Los recursos habrían provenido de fuentes ilegítimas y se habrían distribuido y administrado por parte de empresas mercantiles, particularmente, del Banco Monex, S.A., Institución de Banca Múltiple; Soriana, S.A. de C.V. y tarjetas telefónicas "Premium Platino", así como del gobierno del estado de Zacatecas.

No obstante, el Tribunal Electoral del Poder Judicial de la Federación determinó que las pruebas aportadas por la coalición demandan-

1 El juicio de inconformidad denominado "recurso madre", solicitaba la nulidad o la "no validez" de la elección de presidente de los Estados Unidos Mexicanos, por violación a los principios constitucionales de elecciones auténticas y sufragio libre y por la cancelación del registro de candidato al C. Enrique Peña Nieto por rebase de topes de gastos de campaña. El recurso se presentó ante el Instituto Federal Electoral el 12 de julio de 2012, y el Tribunal lo clasificó como el SUP-JIN-359/2012.

2 El tope de gastos de campaña para la elección de presidente de la República Mexicana fue de $\$ 336112084.16$. 
te no fueron suficientes para acreditar la compra y coacción del voto, ni la aportación ilícita de empresas de carácter mercantil, ni el rebase de topes de gastos de campaña. Por lo anterior, declaró infundados todos los planteamientos y argumentos vertidos sobre este asunto por la coalición Movimiento Progresista.

A pesar de que el Tribunal Electoral validó la elección presidencial, el debate sobre el uso de recursos ilícitos en las campañas electorales continúa vigente, incluso en los niveles institucionales. Por ejemplo, la Cámara de Diputados aprobó en noviembre de 2012 la conformación de la Comisión Investigadora de la Comisión Nacional para la Protección de los Usuarios de los Servicios Financieros (Condusef), que dará seguimiento a las denuncias contra Monex por el reparto de tarjetas prepagadas y la presunta triangulación de recursos en la campaña presidencial del PRI.

Por su parte, el Pacto por México, signado por el presidente de la República y los presidentes de los partidos Revolucionario Institucional, Acción Nacional y de la Revolución Democrática, también contempla, como parte de los acuerdos para la gobernabilidad democrática, el compromiso de impulsar una reforma electoral que permita fortalecer la legislación, para evitar el uso de esquemas financieros y/o recursos de origen ilícito con el propósito de inducir y coaccionar el voto.

Este tema será uno de los mayores desafíos de la reforma electoral que viene, toda vez que el uso del dinero en los procesos electorales está relacionado con diversos dilemas que los partidos deben de enfrentar en cada elección y que podrían afectar a todos los partidos. En el origen, fortalecer el esquema de fiscalización de los recursos partidistas, o establecer mayores limitaciones al financiamiento privado constituyen armas importantes para el control de los ingresos y los gastos, siempre y cuando existiera un esquema fiscal que permitiera a las autoridades encontrar en breve tiempo los elementos adecuados para fiscalizar y auditar los recursos empleados. Desde 1996, cuando la ley incluyó la fiscalización de los recursos de los partidos de manera efectiva, el Instituto Federal Electoral ha requerido de una labor conjunta con autoridades gubernamentales en materia de inteligencia financiera, y el establecimiento de reglas que fortalezcan las obligaciones de los partidos políticos en materia de transparencia y rendición de cuentas, o que además faciliten la participación de la ciudadanía para denunciar posibles hechos ilícitos. 
A diferencia de otras democracias, México optó por un esquema restrictivo en el uso del dinero en los procesos electorales. Las lecciones de 2012 apuntan al reforzamiento de ese tipo de medidas, como el establecimiento en la ley de medidas más estrictas para monitorear el gasto en anuncios espectaculares, por ejemplo; o la prohibición de repartir cualquier tipo de la llamada propaganda utilitaria durante las campañas (desde gorras y camisetas, hasta despensas y artículos para la construcción); o medidas más radicales como la elaboración de un padrón previo de proveedores de bienes para las campañas que sería supervisado por el IFE y la Unidad de Fiscalización.

Algunas de estas medidas ya se pusieron sobre la mesa de debates para diseñar la nueva reforma. Con todo, siempre resultó más fácil la redacción de las normas que su aplicación. En este mismo sentido, una reglamentación estricta que permita brindar orden y disciplina a la forma de gastar el dinero durante las campañas y, posteriormente fiscalizarlo adecuadamente, implica establecer otro tipo de mecanismos de supervisión.

Durante la campaña de 2012 y su validación por parte del Tribunal Electoral del Poder Judicial de la Federación, surgió un nuevo debate que genera a su vez dilemas importantes: la interposición de quejas sobre el uso de recursos durante las campañas, no tiene ningún efecto en la elección misma y la Unidad de Fiscalización del IFE no tiene obligación alguna de resolver los casos en un plazo específico. En consecuencia, como ocurrió en este año, las investigaciones sobre las presuntas ilegalidades en el financiamiento y gasto de la campaña del entonces candidato Enrique Peña Nieto no están terminadas, aún después de un mes de que tomó posesión como presidente de la República.

La experiencia del Instituto Federal Electoral al respecto se remonta al caso denominado "Amigos de Fox", que sirve para ejemplificar el tipo de dilema que enfrentarán los legisladores, si quisieran resolver el problema. Por un lado, violar la ley en materia de ingreso y egreso de recursos durante una campaña, en particular el rebase del tope de gastos establecido, tiene consecuencias para el o los partidos que postularon la candidatura, no para el candidato (independientemente de que haya triunfado o no). En segundo lugar, las presuntas violaciones no tienen efecto alguno sobre los triunfos que pudieran haberse alcanzado con el uso de recursos ilícitos. En tercer lugar, la autoridad electoral arriba al conocimiento de estos ilícitos después de que el proceso electoral ha terminado y los ganadores ya están gobernando. 
La fórmula para solucionar estos males ya se ha ensayado, al menos parcialmente en algunas entidades del país. Por ejemplo, en el Distrito Federal, la violación a los topes de gastos de campaña implica que el candidato ganador pierda su triunfo. Sin embargo, lo que se pone en riesgo es la calidad de la fiscalización que pudiera realizar en muy poco tiempo la Unidad de Fiscalización del IFE y los mecanismos para contar con resoluciones firmes. En el caso "Amigos de Fox", interpuesto por el PRD por el financiamiento ilegal de la campaña del candidato ganador, la Comisión de Fiscalización del IFE buscó resolver lo antes posible el recurso interpuesto. Sin embargo, eso no se lo logró sino hasta después de que Vicente Fox había ocupado la silla presidencial. Adicionalmente, la resolución del IFE, en una primera instancia, resultó absolutoria de las acusaciones interpuestas por el PRD. Fue el Tribunal Electoral el que resolvió devolver el caso a la Comisión de Fiscalización y le ordenó realizar una investigación más a fondo de lo ocurrido con las finanzas del PAN y del PVEM. Para realizar adecuadamente las investigaciones, el IFE tardó en total casi tres años.

Ciertamente los recursos de investigación ahora podrían ser más eficientes que hace 12 años, pues se cuenta con la liberalización de los secretos bancario, fiscal y fiduciario. Sin embargo, aún en esos casos, la ley otorga a las autoridades hasta 30 días para responder a las solicitudes de la Unidad de Fiscalización del IFE. Ese tiempo no se corresponde con la celeridad que se requeriría para resolver en tiempo asuntos de tal trascendencia, si se quisiera anular una elección presidencial con base en este tipo de argumentos.

Este es el tipo de dilemas que tendría que enfrentar el equipo de legisladores que redacten la reforma en esta materia. Por otro lado, si se aborda el tema por la vía de fiscalizar los gastos de campaña durante la campaña misma, lo que se requerirá sería la instrumentación de costosos mecanismos de monitoreo y supervisión por parte de la autoridad que prácticamente tendrían que acompañar la administración de la campaña para prevenir cualquier ilícito posible. Dependerá del esquema que se proponga la efectividad que la nueva ley pudiera tener.

La relación entre democracia y el uso del dinero es un tema que casi ninguna democracia ha logrado resolver del todo. Una vez más será necesario cuidar el equilibrio conveniente entre contar con un buen aparato fiscalizador, eficiente, oportuno y profesionalizado, sin impedir el buen desarrollo de las campañas, el debate y las estrategias de convencimiento al elector que deben de caracterizar a toda democracia. 


\section{La participación de los medios de comunicación}

Durante el proceso electoral de 2012, el acceso de los partidos a la radio y la televisión se llevó a cabo conforme a la ley electoral. Como parte de su obligación de otorgar tiempos al Estado, cada estación de radio y canal de televisión transmitió, a partir del inicio de las precampañas electorales, el 18 de diciembre de 2011 y hasta el día de la jornada electoral, noventa y seis promocionales diarios con contenidos de partidos políticos y autoridades electorales de todo el país, distribuidos entre las seis de la mañana y las doce de la noche. ${ }^{3}$

Estas transmisiones también incluyeron contenidos relacionados con las elecciones concurrentes que se llevaron a cabo en dieciséis entidades de la República. ${ }^{4}$ En cada caso, el IFE fue cuidadoso, a través del Comité de Radio y Televisión, de respetar los calendarios electorales de cada entidad y emitir las órdenes de transmisión precisas para evitar cualquier tipo de inequidad en la competencia electoral entre los partidos.

De acuerdo con los reportes del Instituto Federal Electoral, el cumplimiento por parte de las emisoras de radio y televisión fue del $97.08 \% .^{5}$ Estas cifras permiten afirmar que el modelo de comunicación a través de los tiempos del Estado en ambos medios, funcionó adecuadamente. El modelo, con base en cinco años de experiencia desde la reforma electoral, permitió que no existiera compra de spots por parte de los partidos políticos, ni injerencia de actores externos en la adquisición de espacios para los institutos en competencia. Sin embargo, al igual que en 2006, el uso o participación de los medios de comunicación en el proceso electoral de 2012 causó serias inconformidades antes, durante y después de las campañas.

La principal discusión sobre el tema tuvo como origen el uso de la televisión y la erogación de recursos para la compra de espacios en este medio por parte del Gobierno del Estado de México durante el mandato de Enrique Peña Nieto entre 2005 y 2011, así como la

3 En la cobertura participaron 2335 estaciones de radio y televisión de todo el país. En total, los medios tenían la obligación de transmitir, desde el inicio de las precampañas hasta el día de la jornada electoral, 44159520 spots en toda la República Mexicana.

4 Campeche, Chiapas, Colima, Distrito Federal, Estado de México, Guerrero, Guanajuato, Jalisco, Morelos, Nuevo León, Querétaro, San Luis Potosí, Sonora, Tabasco, Yucatán y la elección extraordinaria de Morelia, Michoacán.

5 Instituto Federal Electoral, Comunicado de prensa del 2 de agosto de 2012. 
supuesta "adquisición encubierta" que llevó a cabo el PRI en radio, televisión y revistas especializadas para promover a su candidato a la Presidencia, durante las campañas electorales de 2012.

La coalición Movimiento Progresista y los representantes de los partidos que la integraban, PRD, PT y Movimiento Ciudadano, manifestaron que estas conductas afectaron:

El derecho a la información de los ciudadanos, constituyendo una forma de presión a los electores que atentó en contra de la libertad del voto en la elección de Presidente de la República, que le permitió a la coalición electoral Compromiso por México y a su candidato a la Presidencia de la República obtener el mayor número de votos... ${ }^{6}$

La coalición también se quejaba de la presunta violación a los principios constitucionales de protección de los derechos "de acceso a la información, del voto libre e informado, así como a los principios republicanos de democracia representativa y de la renovación del Poder Ejecutivo mediante elecciones libres, auténticas y periódicas". ${ }^{7}$

Por su parte, el Tribunal Electoral del Poder Judicial de la Federación declaró como infundados todos los conceptos de nulidad aducidos por la coalición Movimiento Progresista. A decir de la máxima autoridad jurisdiccional, la difusión que el ex gobernador del Estado de México llevó a cabo en los medios de comunicación antes de 2007, no estaba regulada por la ley vigente. En otras palabras, no era ilegal que se promocionara las actividades de Enrique Peña Nieto, incluso a través del uso de campañas organizadas por el Gobierno del Estado de México. En consecuencia, la autoridad electoral jurisdiccional argumentó que no era posible aplicar las normas constitucionales y legales de manera retroactiva. Por otra parte, en relación con la acusación que responsabilizaba al candidato de la coalición Compromiso por México de beneficiarse de apariciones en radio, televisión y revistas,

${ }^{6}$ Juicio de Inconformidad por nulidad de la elección de Presidente de los Estados Unidos Mexicanos, solicitando la declaración de no validez de esta elección por violación a los principios constitucionales de elecciones auténticas y sufragio libre y por la cancelación del registro de candidato al C. Enrique Peña Nieto por rebase de topes de gastos de campaña presentado ante el Instituto Federal Electoral el 12 de julio de 2012, por la Coalición Movimiento progresista y los partidos del Trabajo y Movimiento Ciudadano, p. 182.

7 Ibidem, p. 183. 
en su calidad de candidato a la Presidencia de la República, el Tribunal Electoral señaló que no se podía inferir fehacientemente la adquisición encubierta para su promoción personalizada, toda vez que no formaba parte de una conducta sistemática por parte de los medios que reflejara indubitablemente esa conducta ilegal.

Adicionalmente, el Tribunal Electoral reconoció que se trata de "una figura pública que por los cargos que ha ocupado en órganos de gobierno (incluso, en otros contextos, como los artísticos y partidarios también es justificable) es razonable que tengan una exposición en los medios de comunicación electrónicos e impresos". Esta afirmación resulta interesante, toda vez que para el Tribunal es evidente que una figura pública es monitoreada por los medios y sus actividades seguidas y comentadas cotidianamente. En consecuencia, no se comprobó algún hecho ilícito con el que los medios de comunicación tendrían que ser cómplices activos del candidato.

En suma, la coalición Movimiento Progresista no acreditó con pruebas suficientes el hecho de que se hubiera llevado a cabo una "adquisición encubierta” de espacios en los medios de comunicación durante las campañas electorales. No obstante, persiste el problema y la suspicacia por parte de la oposición al candidato ganador. Las fuerzas políticas y sociales han advertido que la presencia de los candidatos en la radio y la televisión puede generar inequidad en las contiendas electorales y es necesario hacer algo al respecto. El problema consiste en determinar hasta qué punto la presencia de un personaje en los medios, y con qué contenidos específicos, influye directamente en la voluntad de los electores para determinar su voto en la siguiente elección.

Los contenidos del Pacto por México muestran el reconocimiento de los problemas que persisten en la participación de los medios en los procesos electorales, al señalar la necesidad de que la reforma electoral debiera incorporar a las causales de nulidad de una elección, la compra de cobertura informativa en cualquiera de sus modalidades periodísticas, con la correspondiente sanción al medio de que se trate. Una vez más, este caso muestra que podría resultar más fácil regular que aplicar o interpretar la norma. Encontrar el punto medio no será una tarea fácil.

8 Resolución del Tribunal Electoral del Poder Judicial de la Federación con número de expediente SUP-JIN-359/2012, del 30 de agosto de 2012, p. 117. 
El propio Tribunal Electoral, al resolver distintos recursos de apelación en los últimos cinco años ha ordenado al IFE sancionar a los partidos políticos, candidatos y hasta a un ciudadano ${ }^{9}$ por la transmisión de reportajes, mensajes, cierres de campaña o imágenes que promuevan al partido o candidato. Sin embargo, la mayoría de las veces los criterios utilizados por las autoridades electorales han sido calificados como restrictivos y atentatorios de la libertad de expresión y del derecho a la información.

Cierto que la ley ya establece la prohibición a los partidos y candidatos de adquirir, mediante cualquier medio, tiempos, propaganda o cualquier otro tipo de contenido, no sólo durante las campañas electorales, sino en cualquier tiempo. Sin embargo, no parece haber un esquema de medición que permita distinguir con precisión si el medio está simplemente cubriendo las notas que genera un candidato o una personalidad política, o en efecto, ejerciendo algún tipo de promoción, diseñando una estrategia y con ello beneficiando a un futuro candidato. En 2012, el tema de la protesta era que una empresa televisora había "construido" a un candidato. Si se quiere regular el tipo de apariciones en los medios de quienes eventualmente pudieran siquiera aspirar a ser candidatos a la Presidencia de la República, o a cualquier puesto de elección popular, lo más probable es que las normas no sean suficientemente eficientes, pues justamente lo que un protocandidato y precandidato eventualmente buscará es estar en los medios. Si se quiere evitar la aparición de políticos en los medios, mediante sanciones a los propios concesionarios de la radio y la televisión, el efecto podría ser una disminución de la información sobre la política y los partidos políticos en el debate público.

Por lo anterior, las medidas que se tomen para garantizar el desarrollo de campañas equitativas deberán favorecer el mayor nivel de discusión pública y la ampliación al máximo de la información, las expresiones y opiniones relacionados con asuntos de interés público, de manera que no tengan restricciones que limiten la libertad de expresión.

9 El primer ciudadano sancionado por el Instituto Federal Electoral fue el boxeador Juan Manuel Márquez, por portar el logotipo del PRI en su calzoncillo durante una pelea que se transmitió por televisión un día antes de la jornada electoral de Michoacán, el 13 de noviembre de 2011. 


\section{El uso y la difusión de encuestas}

Otra de las características del proceso electoral de 2012 fue el notable incremento en el número de encuestas publicadas que medían las preferencias electorales de los ciudadanos. ${ }^{10}$ Para cualquier sociedad, el hecho de contar con instrumentos que le permitan conocerse y medirse constituye un avance significativo. Ello tendría que significar también un avance en la calidad de nuestra democracia.

Sin embargo, las encuestas en este año experimentaron un fenómeno novedoso que afectó en diversa medida su credibilidad. No sólo se incrementó el número de encuestas que se realizaron antes y durante las campañas y el mismo día de la elección. Adicionalmente, los medios de comunicación hicieron una amplia difusión de sus resultados, se utilizaron en prácticamente cualquier mesa de análisis político, se compararon mediciones y estrategias, e incluso se midió la eficiencia de las estrategias de los candidatos a partir de los resultados de estos ejercicios. En otras palabras, el electorado contó con un instrumento adicional para preparar y medir su voto. Esto es sano para cualquier democracia moderna.

Con todo, después de la elección se generó la percepción de que las encuestas levantadas a lo largo de la campaña acertaron en la ubicación de los candidatos en el orden de las preferencias, pero no en el tamaño de los porcentajes de la votación que eventualmente obtuvo cada uno. Esto motivó una suspicacia más en la opinión del candidato perdedor.

Esta situación y la pérdida de credibilidad en la calidad de las encuestas se expresó una vez más, en el juicio de inconformidad por nulidad de la elección de presidente de los Estados Unidos Mexicanos, por parte de la coalición Movimiento Progresista y los partidos políticos que la integraban. En el cuarto agravio esgrimido por la Coalición quejosa, se argumentó la "indebida utilización de encuestas a favor del candidato de la coalición 'Compromiso por México', Enrique Peña Nieto, publicadas en los medios masivos de comunicación; mismas

10 El IFE dio a conocer que, para el proceso electoral de 2012, las empresas encuestadoras presentaron a esa autoridad 320 estudios, en comparación con los 131 presentados en el proceso electoral de 2006, lo que representó un incremento del 144\%. Asimismo, de un seguimiento realizado por el IFE desde el inicio del proceso electoral y hasta el 15 de julio de 2012 se detectaron 4433 publicaciones de encuestas. Fuente: Presentación del secretario ejecutivo del IFE en el Foro "Las encuestas electorales: la experiencia del 2012". 
que fueron utilizadas en pro del referido candidato como medios de persuasión, inducción al voto y manipulación a la verdad...."

Las encuestas más señaladas por el impacto, la cobertura y su difusión a través de la televisión fueron las levantadas por la empresa Consulta Mitofsky, difundida a través de Televisa, y GEA-ISA, difundida a través de Milenio TV. Esta última con un impacto mayor, dado que llevó a cabo el seguimiento diario de las preferencias electorales durante toda la campaña.

Por su parte, el Tribunal Electoral al resolver la queja señaló que:

No puede afirmarse categóricamente que las encuestas generan siempre y en cualquier circunstancia un efecto específico a favor o en contra de algún candidato o partido... La experiencia indica que no existe una prueba concluyente que asegure que los sondeos, por sí mismos, influyen de manera unívoca y determinante en el comportamiento del conjunto del electorado, aunque se reconoce que tienen una influencia y un impacto variable en la percepción de la opinión pública... ${ }^{12}$

Asimismo, el Tribunal reconoció que los “errores editoriales” de quienes difunden las encuestas pueden generar críticas a su credibilidad y profesionalismo. Sin embargo, ese hecho no se traduce automáticamente en la configuración de infracciones administrativas que puedan traducirse en irregularidades graves y determinantes para el resultado de la elección. ${ }^{13}$

Con todo, más allá de la resolución del Tribunal Electoral, el debate puso de manifiesto la necesidad de analizar la pertinencia y la eficacia de la regulación existente en materia de encuestas de preferencias electorales.

11 Juicio de Inconformidad por nulidad de la elección de Presidente de los Estados Unidos Mexicanos, solicitando la declaración de no validez de esta elección por violación a los principios constitucionales de elecciones auténticas y sufragio libre y por la cancelación del registro de candidato al C. Enrique Peña Nieto por rebase de topes de gastos de campaña presentado ante el Instituto Federal Electoral el 12 de julio de 2012, por la coalición Movimiento Progresista y los partidos del Trabajo y Movimiento Ciudadano, p. 430.

12 Resolución del Tribunal Electoral del Poder Judicial de la Federación con número de expediente SUP-JIN-359/2012, del 30 de agosto de 2012, p. 53.

13 Ibidem. 
Actualmente, la legislación electoral impone reglas para los encuestadores, quienes tienen la obligación de adoptar los criterios generales de carácter científico, que emita el Consejo General. Asimismo, quien ordene la publicación de las encuestas deberá entregar copia del estudio completo al secretario ejecutivo del Instituto, si la encuesta o sondeo se difunde por cualquier medio. También está prohibido difundir por cualquier medio los resultados de encuestas o sondeos de opinión que den a conocer preferencias electorales, durante los tres días previos a la elección y hasta la hora del cierre oficial de las casillas que se encuentren en las zonas de husos horarios más occidentales del territorio nacional.

Esta regulación resulta excesiva si se compara con las normas en democracias como la de Estados Unidos. En México, los códigos electorales de los estados de la República incluyen contenidos similares y en algunos casos mucho más restrictivos, pues llegan a requerir el depósito de fianzas y obtención de permisos especiales para levantar una encuesta.

Ante el problema que representó la difusión de resultados de encuestas durante el proceso electoral, al menos dos legisladores se han pronunciado por hacer cambios a la regulación actual. Roberto Gil Zuarth del PAN y Martí Batres como parte de la bancada del PRD, pero actualmente integrado a la organización MORENA, plantean mayores restricciones para quien elabore o publique una encuesta. Batres propone de plano una prohibición total para difundir o publicar encuestas por cualquier medio durante todo el periodo de campañas electorales y establece penas de multa o prisión para quien incumpla esta disposición.

Por su parte, el senador Roberto Gil Zuarth propuso establecer mecanismos que incentiven el uso responsable de las encuestas, de manera que los ciudadanos evalúen y critiquen los diferentes trabajos que se difundan sobre preferencias electorales. Para ello, propone mecanismos como la publicación del record histórico de las encuestadoras comparado con los resultados oficiales de las elecciones; la creación de un Comité Técnico de Encuestas y Sondeos de Opinión; que toda persona que difunda encuestas o sondeos, dé a conocer la metodología y patrocinadores; difundir cuando algún partido, precandidato, candidato, servidor público o dirigente partidario hubiere solicitado, ordenado, pagado o donado la elaboración de encuesta o sondeo de opinión, y sea difundida por los medios, y que las empresas que realizan este trabajo sean certificadas con estándares internacionales. 
En ambos casos, los legisladores plantean una mayor regulación a la existente. Evidentemente el gremio de encuestadores se inclina por una menor regulación que justamente permita y facilite el levantamiento adecuado de sus ejercicios para alcanzar mayor precisión en sus resultados. Ciertamente no se trata de que la encuestas se conviertan en pronósticos exactos de lo que ocurrirá el día de la elección, pero sí es necesario que los ejercicios demoscópicos tengan un nivel importante de credibilidad por lo que toca a quien ordena, paga y difunde la información. La metodología empleada debiera ser parte del prestigio del encuestador, pero su revisión ya está en la normatividad actual. Las propuestas apuntan a buscar un mayor compromiso de transparencia y profesionalismo entre los medios de comunicación y los encuestadores, que favorezcan el debate político y la libre circulación de las ideas. Regular de más sólo incidirá en la obstaculización del derecho a informarse de todos los ciudadanos.

\section{Los temas que vienen}

El 8 de agosto de 2012, después de tres años de discusión en las cámaras de Diputados y Senadores, y después de que al menos diecisiete congresos locales lo avalaron, se publicó en el Diario Oficial de la Federación, el Decreto de reforma a la Constitución en materia política.

La propuesta de reforma original hecha por el presidente Felipe Calderón contemplaba diez puntos entre los que se encontraban los siguientes: la reelección consecutiva de alcaldes; la reelección de legisladores; la reducción de integrantes de las cámaras del Congreso de la Unión; el incremento del umbral requerido para que los partidos políticos conserven su registro, y el establecimiento de la segunda vuelta electoral para la elección de presidente de la República. De los temas aprobados en 2012, destacan tres por la posibilidad de brindar a los ciudadanos mayor poder en la toma de decisiones públicas: la iniciativa ciudadana, las candidaturas independientes y la consulta popular.

La iniciativa ciudadana plantea como un derecho de los ciudadanos mexicanos que puedan proponer iniciativas de ley sobre temas de su interés que no se encuentren en la agenda legislativa. Con la incorporación de las candidaturas independientes a la Constitución, se prevé la posibilidad de que los ciudadanos soliciten su registro como candi- 
datos a la Presidencia de la República, sin la intervención de un partido político y, finalmente, con la consulta popular, los ciudadanos podrán expresarse a través del voto sobre temas de interés nacional. Los resultados serán vinculatorios para los poderes Ejecutivo y Legislativo federales y para las autoridades competentes, cuando la participación total corresponda, al menos, al 40\% de los ciudadanos inscritos en la lista nominal de electores.

El propio Decreto señala que el Congreso de la Unión deberá expedir la legislación para hacerlo cumplir, a más tardar en un año contado a partir de la entrada en vigor del mismo. Ese plazo se vence el 8 de agosto de 2013 y en consecuencia, la agenda legislativa deberá regular, al menos, lo siguiente:

a) En materia de candidaturas independientes:

- El procedimiento para el registro de los candidatos independientes.

- Los umbrales para determinar el respaldo ciudadano requerido para ser candidato independiente.

- El monto de financiamiento público al que tendrán derecho, en su caso.

- El uso de financiamiento privado, en su caso.

- Las obligaciones en materia de fiscalización de los recursos empleados en las campañas.

- El tipo de infracciones que puedan cometer y las sanciones correspondientes.

- La forma de acceder a la radio y la televisión.

b) En materia de la consulta popular:

- Establecer las reglas para que el IFE apoye al Congreso en la verificación del requisito relativo al número de ciudadanos que soliciten la realización de la consulta, previsto en el artículo 35, fracción VIII, párrafo 4o., de la Constitución Política de los Estados Unidos Mexicanos.

- Establecer los procedimientos para la organización y logística de la consulta popular el mismo día de la jornada electoral federal.

c) En materia de la iniciativa ciudadana:

- Establecer las reglas para apoyar al Congreso en la verificación del cumplimiento del número de ciudadanos que pretenden iniciar una ley $(0.13 \%$ de la lista nominal de electores). 
Los dilemas que la construcción de este tipo de regulación plantea no son menores. En los tres casos se trata de ensanchar la participación ciudadana mediante un posible costo para los partidos políticos en la competencia por el poder. Surge aquí una vez más el dilema en relación con la equidad en la competencia que tendrá que ser resuelto por los legisladores, so pena de hacer nulas las reformas alcanzadas.

El ejemplo más claro de este dilema es la decisión de otorgar o no financiamiento público a los candidatos independientes que busquen participar en una elección. Otorgar este financiamiento, más allá del problema de definir su monto, implica aplicar dos criterios diferentes en el sistema: a los candidatos de los partidos se les otorga financiamiento con base en los recursos de sus partidos, pero queda al arbitrio de los partidos mismos otorgar recursos o no a sus candidatos, dependiendo de su potencial de triunfo; por otro lado, los candidatos independientes tendrían, por definición, financiamiento directo garantizado, independientemente del número de candidatos que se presentaran.

El siguiente dilema tiene que ver con la campaña misma. Un candidato de partido se beneficia naturalmente de la campaña genérica que emite su partido, mientras que un candidato independiente no cuenta con ese tipo de infraestructura. Evidentemente ese sería el costo de no sumarse a una fuerza electoral, pero ambos tipos de candidatos tendrían que rendir cuentas de los recursos que recibieran por parte del erario público.

Finalmente, otro de los dilemas a resolver es la participación o no de los candidatos independientes en los medios de comunicación. En este caso, a diferencia del financiamiento público que puede ser definido e incrementado con base en las decisiones del IFE y las disposiciones legales, los tiempos en los medios de comunicación son finitos. Los espacios públicos en televisión, por ejemplo, no pueden ser superiores a 48 minutos diarios y cualquier disposición de estos tiempos para candidatos independientes implica una reducción en los tiempos de los partidos.

Los dilemas en los casos de la consulta popular y la iniciativa ciudadana no son menores, pues implican una definición muy clara de las competencias de las autoridades electorales al respecto, ya sea solo para verificar el cumplimiento de los requisitos que establezca la ley en términos de firmas de solicitantes, o ya sea por la organización misma de los procesos. Una vez más, se antoja que prevalezca el equilibrio en 
las decisiones que tomen los legisladores al cumplir el mandato de ley de tener estos elementos listos antes del 8 de agosto de 2013.

\section{Conclusiones}

Los temas a considerar para una reforma electoral, no sólo tienen que ver con los problemas detectados en el proceso electoral de 2012, sino que se derivan de distintas situaciones:

a) Aquellas propuestas que buscan mejorar la ley electoral de 20072008, a partir de las experiencias electorales federales de 2009 y de 2012, así como las experiencias electorales locales en los últimos cinco años.

b) Las normas que deben regularse a raíz de la reforma política aprobada el pasado mes de agosto, en la que se incorporan a la Constitución las figuras de candidatura independiente, iniciativa ciudadana y consulta popular.

Los partidos políticos, los medios de comunicación, los empresarios, los encuestadores y otros sujetos regulados tienen intereses diferentes en el alcance de la reforma electoral. Todos, en particular, los partidos, lucharán por liderar el proceso de cambio y negociar en las mejores condiciones los términos de la redacción final. Cualquier propuesta que se presente tendrá mayores efectos si cumple con los siguientes requisitos:

a) Integralidad. Revisión no sólo de artículos aislados del Código Electoral, sino de su integralidad y técnica jurídica.

b) Definición clara y precisa de los temas prioritarios para la reforma, que incorporen alternativas a las propuestas que se formularán en todos los partidos.

c) Claridad del cronograma para la construcción y aprobación de la reforma, tomando en consideración los eventos políticos que acompañarán la discusión de cualquier propuesta.

d) Partir de una negociación interna entre los actores interesados en participar, de manera que se defiendan los temas centrales. 
En el caso del uso los medios de comunicación, se deberá analizar si el restrictivo modelo de comunicación política es adecuado o no y si es necesario modificar el modelo, para cambiarlo completamente. No sólo se trata de reformar los artículos que han generado alguna controversia. Lo ideal será liberalizar al máximo el uso de los medios de comunicación a fin de privilegiar el debate político, el derecho a la información y la libertad de expresión.

En materia de financiamiento y fiscalización de los recursos de los partidos políticos durante las campañas, de manera contraria al uso de los medios, es necesario acotar el uso del dinero y generar prácticas que permitan transparentar el gasto durante las campañas. Para ello, será necesario, entre otros temas: modificar los plazos para la presentación de informes de gastos y para su revisión por parte del IFE; establecer mecanismos para evitar el rebase de topes de gastos de campaña; establecer mecanismos expeditos para fiscalizar el gasto en medios de comunicación distintos a la radio y la televisión; contar con un órgano de dirección en el que se tomen las decisiones en materia de fiscalización de los recursos de los partidos, y evaluar la posibilidad de dar más injerencia al Consejo General en materia de fiscalización, para desconcentrar las decisiones que toma la actual Unidad de Fiscalización de los Recursos de los Partidos.

En materia de encuestas, a partir de la experiencia de 2012, será importante analizar la conveniencia de transparentar la información sobre la cadena: orden, elaboración, reporte, publicación y difusión de las encuestas durante un proceso electoral, y establecer un mecanismo adecuado para dar seguimiento a los recursos utilizados en los ejercicios de encuestas, encuestas a salida de casilla y conteos rápidos, todo ello sin restringir el levantamiento y la publicación de estos ejercicios.

Estos asuntos deberán conciliarse con la reforma en materia política recientemente aprobada y que requiere de una nueva regulación para instrumentar la consulta popular, la iniciativa ciudadana y las candidaturas independientes.

Por otra parte, se deberán considerar los acuerdos para la gobernabilidad democrática previstos en el Pacto por México, que toman en cuenta mecanismos para brindar transparencia y racionalización al gasto de los partidos durante las campañas, así como al uso de los medios de comunicación, tanto por parte de los partidos, como de los funcionarios públicos. 
El gran reto será armonizar todas las normas de manera que las nuevas disposiciones se integren a las disposiciones actuales y a las reglas por modificar, a fin de garantizar derechos fundamentales como la libertad de expresión y el derecho a la información, al mismo tiempo que se limite el uso del dinero durante las campañas. Sólo así seguiremos avanzando hacia una democracia con calidad.

\section{Bibliografía}

Instituto Federal Electoral, Acuerdo del Consejo General por el que se actualiza el tope máximo de gastos de campaña para la elección de Presidente de los Estados Unidos Mexicanos para el proceso electoral federal 2011-2012 en cumplimiento al resolutivo segundo del acuerdo identificado con el número CG382/2011, del 16 de diciembre de 2011.

Juicio de Inconformidad por nulidad de la elección de Presidente de los Estados Unidos Mexicanos, solicitando la declaración de no validez de esta elección por violación a los principios constitucionales de elecciones auténticas y sufragio libre y por la cancelación del registro de candidato al C. Enrique Peña Nieto por rebase de topes de gastos de campaña presentado ante el Instituto Federal Electoral el 12 de julio de 2012, por la Coalición Movimiento progresista y los partidos de la Revolución Democrática, del Trabajo y Movimiento Ciudadano.

Resolución del Tribunal Electoral del Poder Judicial de la Federación con número de expediente SUP-JIN-359/2012, de fecha 30 de agosto de 2012.

Decreto por el que se reforman y adicionan diversas disposiciones de la Constitución Política de los Estados Unidos Mexicanos, en materia política, publicado en el Diario Oficial de la Federación el 9 de agosto de 2012. 